P\&A Año 2, N²

enero-junio de 2017

pp. $17-28$

\title{
Resumen
}

Los medios digitales, en tanto lugares comunes de intercambio y comunicación, se han convertido en los espacios idóneos y naturales para ejercer la crítica de arquitectura. En el escenario peruano, este fenómeno, que comienza a manifestarse, presenta características particulares en cuanto a sus principales aspectos e indicadores, como autoría, objetivo, medio, temática, profundidad, método, estilo, alcance y sostenibilidad. El análisis de estos muestra que, de acuerdo con las tendencias del contexto global, en la crítica de arquitectura en el Perú empiezan a aparecer nuevas facciones, las cuales cuestionan la ideas convencionales de crítica, e intercambio de información y opiniones, incluso en el escenario educativo-universitario, lugar donde la crítica venía germinándose en su concepción tradicional.

Palabras clave: Crítica, arquitectura, medios digitales

\section{Crítica de arquitectura en el Perú: Los medios digitales como proyección del espacio académico*}

\author{
Architectural criticism in Peru: Digital media as a projection of the academic space \\ MSc. Arq. Israel Romero Alamo**
}

Recibido: 10 de abril de 2017

Aceptado: 5 de junio de 2017

\begin{abstract}
Digital media, inasmuch as it is a common place of exchange and communication, has turned into the most suitable and natural space to exercise the criticism of architecture. In the Peruvian setting, this phenomenon, which is starting to play out, shows particular characteristics in terms of its main aspects and indicators, such as authorship, goal, medium, subject matter, depth, method, style, scope and sustainability. The analysis of these aspects demonstrates that, in accordance with global trends, architectural criticism in Peru has started to exhibit new factions. They question the conventional ideas of criticism, and exchange of information and opinions, even in educational/university settings, where critique had been developing in its traditional fashion.
\end{abstract}

Keywords: Criticism, architecture, digital media

\footnotetext{
* Basado en la tesis de maestría en Arquitectura-Historia, Teoría y Crítica (La Crítica de Arquitectura en el Perú desde Plataformas Digitales Interactivas. Evaluación de su Sistema de Producción) de la Facultad de Arquitectura Urbanismo y Artes de la Universidad Nacional de Ingeniería. 2016, Lima, Perú. Es una investigación autofinanciada. Se declara no tener conflicto de intereses en la publicación de este artículo.

** Arquitecto por la Universidad César Vallejo (2011), maestro en Ciencias con mención en ArquitecturaHistoria, Teoría y Crítica por la Universidad Nacional de Ingeniería (2016). Profesor en la Universidad Cesar Vallejo, Universidad Privada del Norte y Universidad Peruana Unión.
} 
Desde que alcanzó protagonismo, la comunicación digital está generando una manera distinta de intercambiar información y emitir opiniones, hasta el punto que lo presencial, aquello muchas veces entendido como "real", pareciera quedar relegado o perder importancia. Ello se debe a que el mundo digital es un espacio que ofrece más posibilidades que el tangible. Por ejemplo, su naturaleza permite que el tiempo y el espacio dejen de ser limitaciones para establecer relaciones, así como la carencia de restricciones y filtros para poder emitir una opinión.

El presente trabajo resume una primera indagación respecto de la crítica de arquitectura, particularmente aquella desarrollada en medios digitales peruanos en tanto una proyección de los espacios académicos convencionales. Para el análisis se ejecutó un levantamiento de los sitios en los que se llevaba a cabo tal crítica entre los años 2004 y 2016, tanto blogs como redes sociales.

Por tratarse de un tema relativamente nuevo dentro del escenario arquitectónico peruano, se empleó una metodología exploratoria y la finalidad planteada se definió como informativa. Se tomaron ejemplos puntuales de espacios y publicaciones para identificar de qué manera estos responden a los distintos indicadores comunes de la crítica, independientemente del medio de publicación.

\section{Crítica, pedagogía y didáctica}

La crítica "constituye una actividad con el más amplio sentido cultural. Su misión es la de interpretar y contextualizar" (Montaner, 2007, p. 11), en este caso, un hecho arquitectónico. Así, la crítica puede darse en cualquier tipo de contexto en el que exista intercambio de información o socialización de posturas.

Los espacios académicos son naturalmente los lugares idóneos para el intercambio de información y posturas diversas. Esto tiene una estrecha relación con la crítica; de hecho, en el campo de la arquitectura, la crítica es una práctica constante que se da en distintos niveles (Stroeter, 2005). Es quizá la manera más recurrente en que se busca mejorar constantemente tanto del producto académico como el factor humano.

No obstante, la crítica no debería limitarse a estos espacios, sino que "debe dirigirse al público y no solo al reducido medio de los profesionales o los especialistas" (Toca, 2011, párr. 5), quienes en definitiva conforman, en conjunto, a los actores de la ciudad.

Por este motivo, Elio Martuccelli (comunicación personal, 2014) considera que la crítica de arquitectura debería tener un fin didáctico; es decir, debería contemplar, más allá de la simple emisión de un juicio de valor, una postura que permita entender el hecho arquitectónico y la realidad que lo contiene, para así apostar por una mejora integral.

En estos aspectos se centra la principal relación entre la crítica de arquitectura y los espacios académicos, y su extensión al mundo exterior.

\section{La crítica de arquitectura en los medios digitales}

Frente al desarrollo comunicativo y académico convencional desarrollado en las aulas universitarias y en medios tradicionales físicos, aparece, como variante y extensión, su desarrollo en los medios digitales, que no son ni presenciales ni estáticos. En los espacios académicos y tradicionales se supone que existe una comunicación horizontal y con cierta fluidez; sin embargo, esta, por fuerza mayor, se muestra comúnmente unilateral, y en ella predomina el dar y recibir información de forma independiente. En el mundo digital lo unilateral se desvanece para dar paso a escenarios completamente distintos, donde cualquier persona que cree su espacio puede emitir una opinión que, al menos en primera instancia, puede tener el mismo valor o importancia que cualquier otra (Lash, 2002).

\section{Características de la crítica en los medios} digitales

Las características del producto crítico en un medio digital como la web 2.0 (la de mayor 
uso hoy, la cual emplean blogs y redes sociales) son particulares, principalmente por la ambivalente relevancia de lo mediático (el fin válido de socializar información) en tanto fortaleza y a la vez debilidad.

\section{Autoría}

La autoría de la crítica en una plataforma digital es muy distinta de esta en medios tradicionales. Ello se debe a que el espacio digital otorga a la crítica la efectividad del anonimato, lo cual es sumamente difícil cuando se trata de un medio tradicional. De la misma forma, pero con mayor facilidad de producción, la crítica en un medio digital avala la publicación con diversos números de autores. Además, la característica y variante principal de la crítica en la web 2.0 es que permite la difusión sin un filtro de autoría. Esto quiere decir que cualquier usuario de la red puede abrir un espacio y efectuar en él una crítica sin la necesidad de un comitente o de un sistema productivo más complejo.

\section{Objetivo}

La crítica desarrollada en la web 2.0 puede estar influida en gran medida por el llamado fin mediático o por la búsqueda de una suerte de fama virtual, obtenible mediante la visibilidad en páginas de redes sociales o en canales de YouTube. Así, es posible que el motivo del autor de la crítica sea básicamente mediático y no precisamente académico, el cual suele ser el principal objetivo de la crítica en medios tradicionales.

Medio

En las plataformas digitales, la clase de medios utilizados corresponden a diversos tipos de espacios ofrecidos -básicamente- de manera gratuita por empresas que obtienen un rédito económico según la cantidad de usuarios que utilicen sus plataformas, así como por medio de la publicidad.

\section{Temática}

La libertad de publicación que ofrece un medio digital como un blog o una red social permite una diversidad temática muy amplia, la cual depende casi exclusivamente del propio crítico. Es decir, no existe necesariamente, como en un medio físico (un diario o una revista, por ejemplo), el requerimiento de un tema limitado por la línea editorial.

\section{Profundidad}

De igual forma, en el espacio virtual el crítico tiene la facultad de decidir el enfoque y la rigurosidad de la crítica que plantea: si solo se centra en un análisis descriptivo, en la emisión de un juicio de valor, o si, adicionalmente, opta por la proposición. La gratuidad de un medio como el digital suprime casi por completo las restricciones en cuanto a la profundidad. La crítica es producida y editada por el propio crítico. También ocurre que la profundidad de la crítica puede verse "sacrificada" ante la flexibilidad o falta de rigurosidad cuando el medio es tan fugaz como una red social o un blog.

\section{Método}

En los medios digitales la longitud de un texto crítico es un factor determinante para que este pueda ser consumido por una gran cantidad de público. Esto se debe principalmente al enorme y constante flujo de información que recorre los medios digitales. Por ello, un lenguaje básicamente visual, breve, suele ser siempre más efectivo en este tipo de plataformas.

\section{Estilo}

Uno de los énfasis de la crítica en medios digitales es que el estilo de esta puede convertirse en uno de los mecanismos más potentes para hacerla efectiva. En el mundo virtual, la crítica "políticamente incorrecta" se emplea frecuentemente, utilizando muchas veces el anonimato como pieza clave. Este hecho, prácticamente imposible en una publicación física, hoy se ha convertido en una polémica potencialidad.

\section{Alcance}

Una crítica emitida en un blog o en una red social puede convertirse en un hecho "viral", pues puede ser "compartido" por miles de usuarios incluso pocos minutos después de su publicación, sin costo alguno. Su potencial 
alcance es mucho mayor que el de una publicación física. No obstante, esto relativiza su sostenibilidad. Puede que el crítico efectúe su labor sostenidamente, como puede que la crítica sea eventual. No existe mayor restricción que controle la sostenibilidad, una constancia mínima.

\section{Sostenibilidad}

La sostenibilidad en la web 2.0, a diferencia de en los medios tradicionales, cuenta también con muchas variantes. En primer lugar, esta puede depender exclusivamente del autor, quien se encuentra inmerso en una plataforma del ciberespacio que aparentemente no tiene límites. Sin comitentes ni editores, el autor de la crítica tiene la potestad de mantener sus publicaciones durante un largo tiempo, darlas de baja o discontinuarlas. No hay un límite temporal establecido ni la exigencia por mantener algún tipo de parámetro de frecuencia para las publicaciones.

\section{La crítica de arquitectura en medios digitales peruanos}

Teniendo en cuenta la fecha de inicio del fenómeno digital a raíz de la creación de la web 2.0 (2004), se ha podido identificar en el espacio de la arquitectura peruana, hasta fines de 2016, un número importante de espacios virtuales $^{1}$ en los cuales se ejercía la crítica en distintas medidas y con distintas intensidades. Muchos de estos habían sido planteados por estudiantes de Arquitectura o, en su defecto, arquitectos jóvenes, población que domina este tipo de espacios.

En la Tabla 1 están consignados muchos de los espacios en los que se realiza crítica arquitectónica en el Perú. Existe una presencia importante de blogs que fueron creados durante el periodo comprendido entre 2011 y 2016. Aunque la presencia de Lima es determinante, se visibiliza variedad de orígenes. Esto tiene una estrecha relación con la cantidad poblacional de las ciudades, así como con

1 Debido a su fugacidad, de fácil creación y dominio, el número varía constantemente, por lo que en la actualidad (2017) algunos de estos espacios han desaparecido, mientras que se han creado otros nuevos. la cantidad de facultades o escuelas de Arquitectura existentes. Así, ciudades como Arequipa, Trujillo, Chiclayo y Huancayo tienen una presencia relevante en estos espacios.

\section{El producto de la crítica en medios digitales peruanos}

En el Perú, la crítica desde medios digitales se ejerce a partir de distintos formatos. Para la presente investigación se tomó como muestra siete espacios web: los blogs Divagarquitectura, Citio, Habitar, Tipos (In)Urbanos y Lugares Comunes; y las páginas en redes sociales Lucho Gris, Arquitecto Peruano y Grandes Éxitos de la Arquitectura Peruana.

El producto de la crítica en medios digitales peruanos, según los indicadores planteados anteriormente (autoría, objetivo, medio, temática, profundidad, método, estilo, alcance y sostenibilidad), aplicables a cualquier situación de la crítica, adquiere las características particulares que pueden observarse en la Tabla 2 y se detallan a continuación.

Según el tipo de autor

Un importante porcentaje de artículos o críticas publicadas en las plataformas digitales manifiestan su autoría de forma pública (indicando sus nombres y apellidos). El uso de seudónimos, utilizado eventualmente por blogs como Citio, por ejemplo, se convierte en una suerte de marca que valida prontamente la crítica, gracias a sus antecedentes, los logros proyectuales o académicos del grupo o sujeto que se identifica mediante dicho sello. Para Javier Vera, de Citio, se trata de un fenómeno negativo, porque genera una reacción automática frente a la crítica. Esta muchas veces es aprobada sin siquiera ser leída a cabalidad, un hecho bastante común en las publicaciones en estos medios. La sobreinformación relativiza el contenido, convirtiéndolo en algo de menor relevancia, lo cual da la impresión de que el título es lo único "necesario" que leer.

Tanto para Lucho Gris y Arquitecto Peruano-quien usa seudónimo y se mantiene en el anonimato- como para Grandes Éxitos de la Arquitectura Peruana, el anonimato es vital 
para la producción de crítica. Afirman los autores de dichas páginas que sin el anonimato tendrían que reducir en gran medida el estilo provocador y la frontalidad de sus críticas (comunicación personal, marzo, 2016). No podrían emitir con libertad críticas dirigidas, con nombres y apellidos, a obras o arquitectos por temor a las represalias.

Ante la elección de realizar una crítica frontal, el anonimato otorga al crítico la posibilidad de convertirse en un ente difuso, casi imposible de replicar, lo que le brinda un alto grado de libertad para operar, como efecti- vamente hacen las páginas mencionadas. Sin embargo, es importante resaltar que el hacer pública la autoría no quiere decir que la crítica se convierta automáticamente en impersonal, genérica o voluble. Existen claros ejemplos que indican lo contrario, como lo han hecho reiteradas veces los miembros de Citio o Cristina Dreifuss (Divagarquitectura). La crítica en estos casos parte de iniciativas personales, donde el crítico considera pertinente ser frontal. No obstante, sigue presente el temor a las represalias de parte de los sujetos criticados.

Tabla 1. Resumen de espacios que hacen crítica de arquitectura en el Perú

\begin{tabular}{|c|c|c|c|c|}
\hline$N^{\circ}$ & Blog & Plataforma & Origen & Duración \\
\hline 1 & Divagarquitectura & Blogspot & Lima & 2007-Actualidad \\
\hline 2 & Arquitectura Huachafa & Blogspot & Lima & 2009-Actualidad \\
\hline 3 & Catarqsis Urbana & Blogspot & Lima & 2011-2014 \\
\hline 4 & Nomos & (propia) & Lima & $2013-2014$ \\
\hline 5 & M.M. Arquitectura/Atelier & (propia) & Trujillo & 2012-Actualidad \\
\hline 6 & La Chimenea & Blogspot & Chimbote & 2012-Actualidad \\
\hline 7 & Pirqas & Wordpress & Lima & 2013-Actualidad \\
\hline 8 & Citio & Blogspot & Lima & 2008-2012 \\
\hline 9 & Maquetas Aparte & La Mula & Lima & 2014-Actualidad \\
\hline 10 & TiPos (In)urbanos & Wordpress & Arequipa & $2013-2014$ \\
\hline 11 & Habitar & Blogspot & Lima & 2010-Actualidad \\
\hline 12 & Trampantojo & Blogspot & Arequipa & 2014-Actualidad \\
\hline 13 & Arquitectura Moderna & Blogspot & Chiclayo & 2009-Actualidad \\
\hline 14 & Patrimonio Berrinchudo de la Humanidad & Blogspot & Lima & 2014-Actualidad \\
\hline 15 & Hanan Wanca & Blogspot & Huancayo & 2011-Actualidad \\
\hline 16 & Arquitectura, Espacio y Confort & Blogspot & Huancayo-Lima & $2011-2014$ \\
\hline 17 & Qoto Cix & Wordpress & Chiclayo & $2011-2012$ \\
\hline 18 & La Forma Moderna en Latinoamérica & Blogspot & Trujillo & $2010-2014$ \\
\hline 19 & Laboratorio de Arquitectura-Perú & Blogspot & Trujillo-Lima & $2008-2014$ \\
\hline 20 & Apuntes de Arquitectura & Blogspot & Cusco-Lima & 2008-Actualidad \\
\hline 21 & Medio Chueco & Blogspot & Chiclayo & 2010-Actualidad \\
\hline 22 & La Arquitectura & Blogspot & Lima & 2006-2013 \\
\hline 23 & Arquitectura y Ciudad & (propia) & Lima & 2011-Actualidad \\
\hline 24 & Lugares Comunes & Wordpress & Lima & 2009-Actualidad \\
\hline 25 & Ciudad Fragmento & Wordpress & Arequipa & 2014-Actualidad \\
\hline
\end{tabular}

Elaboración propia. 
Tabla 2. Detalles de la crítica en medios peruanos (por indicadores)

\begin{tabular}{|c|c|c|c|c|}
\hline Indicadores & \multicolumn{2}{|c|}{ Sub-indicadores } & \multicolumn{2}{|c|}{ Resultados } \\
\hline \multirow{7}{*}{ Autoría } & \multirow{3}{*}{ Según el tipo de autor } & Pública & Pública & $71.40 \%$ \\
\hline & & Seudónima & Seudónima & $15.20 \%$ \\
\hline & & Anónima & Anónima & $13.40 \%$ \\
\hline & \multirow{2}{*}{ Según número de autores } & Individual & Individual & $84.00 \%$ \\
\hline & & Grupal & Grupal & $16.00 \%$ \\
\hline & \multirow{2}{*}{ Según el grado de instrucción } & Especialista & Especialista & $100.00 \%$ \\
\hline & & Diletante & Diletante & $0.00 \%$ \\
\hline \multirow{2}{*}{ Objetivo } & \multicolumn{2}{|c|}{ Ejercicio académico-personal } & Académico & $71.50 \%$ \\
\hline & \multicolumn{2}{|c|}{ Ejercicio mediático-social } & Mediático & $28.50 \%$ \\
\hline \multirow{6}{*}{ Temática } & \multicolumn{2}{|l|}{ Edificio } & Edificio & $17.50 \%$ \\
\hline & \multicolumn{2}{|l|}{ Ciudad } & Ciudad & $32.50 \%$ \\
\hline & \multicolumn{2}{|c|}{ Ejercicio profesional } & Ejercicio & $25.00 \%$ \\
\hline & \multicolumn{2}{|l|}{ Teoría } & Teoría & $3.20 \%$ \\
\hline & \multirow{2}{*}{\multicolumn{2}{|c|}{ Otros }} & Coyuntura & $16.00 \%$ \\
\hline & & & Otros & $5.80 \%$ \\
\hline \multirow{3}{*}{ Profundidad } & \multicolumn{2}{|l|}{ Descriptiva } & Descriptiva & $5.50 \%$ \\
\hline & \multicolumn{2}{|c|}{ Con juicio de valor } & C/J. De valor & $89.40 \%$ \\
\hline & \multicolumn{2}{|l|}{ Propositiva } & Propositiva & $5.10 \%$ \\
\hline \multirow{5}{*}{ Método } & \multicolumn{2}{|l|}{ Texto corto } & Texto corto & $59.20 \%$ \\
\hline & \multicolumn{2}{|l|}{ Texto largo } & Texto largo & $16.40 \%$ \\
\hline & \multicolumn{2}{|l|}{ Caricatura } & Caricatura & $14.20 \%$ \\
\hline & \multicolumn{2}{|l|}{ Fotomontaje } & Fotomontaje & $3.00 \%$ \\
\hline & \multicolumn{2}{|l|}{ Foto + texto } & Foto + texto & $7.20 \%$ \\
\hline \multirow{3}{*}{ Estilo } & \multicolumn{2}{|l|}{ Conservador } & Conservador & $13.00 \%$ \\
\hline & Neutral & & Neutral & $45.70 \%$ \\
\hline & Provocador & & Provocador & $41.30 \%$ \\
\hline Modir & Blog & & Bloo & dpress \\
\hline Tivedio & Red social & & & \\
\hline & & Local & Local & $30.20 \%$ \\
\hline & Alcance temático espacial & Nacional & Nacional & $58.20 \%$ \\
\hline & & Internacional & Internacional & $11.60 \%$ \\
\hline & & Limitado & - & - \\
\hline Alcance & & $\begin{array}{c}\text { Regular } \\
\text { (Blogs) }\end{array}$ & Comentarios & 3.6 p/publicación \\
\hline & Alcance social & & Likes & 78 p/publicación \\
\hline & & $\begin{array}{c}\text { Viral } \\
\text { (Redes sociales) }\end{array}$ & Comentarios & 14 p/publicación \\
\hline & & & V. Compartidas & 6 p/publicación \\
\hline et & Irregular & & - & - \\
\hline sosterionita & Constante & & Constante & $1.8 \mathrm{al}$ mes \\
\hline
\end{tabular}

Elaboración propia. 


\section{Según el número de autores}

La crítica emitida en plataformas digitales es prioritariamente individual, escrita a nombre personal por los autores de los blogs. Eventualmente escriben terceras personas que son invitadas. Según el estudio realizado, solo en el $16 \%$ de sitios encuestados se realizan publicaciones firmadas por más de una persona. Estas toman la forma de un manifiesto grupal o de una propuesta crítica que se fortalece al ser emitida desde un grupo humano. Ese es el caso eventual de Citio, donde se realizan colaboraciones al editar algunas críticas, por ejemplo, para desarrollar textos o fotomontajes. Existen trabajos complementarios que validan la conformación de un grupo detrás del seudónimo. Esto enriquece en gran forma la crítica.

Algo similar sucede con el blog arequipeño Tipos (In)Urbanos, pues si bien el grupo de arquitectos publica artículos de forma individual, realiza en conjunto otras críticas que considera de mayor relevancia, donde incluso plantea una propuesta arquitectónica también crítica.

\section{Según el objetivo}

Llama poderosamente la atención que quienes ejercen crítica por un interés académicopersonal $(71.5 \%)$ suelen desarrollarla empleando el blog como plataforma, mientras que quienes la llevan a cabo con un objetivo mediático-social (28.5\%) tienden a valerse de las redes sociales.

Los autores de Citio, Habitar y Divagarquitectura indican que su intención no es mediática, sino que elaboran la crítica por una intención personal, pues el escribir es una de las prioridades de su quehacer profesional. Por ello, según expresan, les resulta de poco interés la amplitud de difusión que sus publicaciones puedan tener, ya que les resulta mucho más importante que quien las lea lo haga por interés propio. Esta afirmación devela una visión relativamente tradicional del quehacer crítico, al margen de que aprovechen las herramientas disponibles actualmente para efectuar lo que hubiese sido difícil en otras épocas, por cuestiones básicamente tecnológicas.

Quienes manifiestan tener un fin básicamente mediático -como los autores de Lucho Gris o Grandes Éxitos- publican en las redes sociales. En este caso, es mucho más fuerte la volatilidad del medio y la exposición constante. Esto genera que los contenidos sean mucho más ligeros y fugaces, para que no se pierdan en el mar de sobreinformación (Eco, 2015) que representa una red social como Facebook.

También es importante indicar que mucho tiene que ver la autoría anónima de estas páginas; esto les permite admitir -contrariamente a lo políticamente correcto- que lo mediático también es un fin válido y de primer orden para la crítica.

\section{Según la temática}

El tema que se aborda con mayor recurrencia en la crítica en redes sociales es el de la ciudad. Un 32\% aborda temas de ciudad, centrados básicamente en el espacio público, la movilidad urbana, entre otros. Blogs como Citio o Lugares Comunes tienen como centro la crítica a la ciudad, tema que si bien está ligado estrechamente a la actividad profesional de sus autores, guarda relación con la preferencia del público (en el $40 \%$ de sitios encuestados se refleja la predilección por la temática urbana).

El edificio ocupa el tercer lugar, con un $17.5 \%$, entre los temas elegidos. Análisis que abordan al edificio de manera integral, como los planteados en publicaciones físicas, son posibles en blogs como Habitar o Divagarquitectura, en los que se realizan críticas sobre una base teórica y juicios de valor de objetos arquitectónicos que los autores consideran pertinentes. El ejercicio profesional es también un tema importante dentro de la crítica. En distintas medidas, la mayoría de los blogs y páginas cuestionan diversos quehaceres profesionales o la actitud de la labor arquitectónica frente a un hecho determinado. Esta es la crítica que tiene mayor repercusión, porque nace en estos espacios, y se manifiesta luego en un hecho concreto y "real". 


\section{Según la profundidad}

A pesar de lo que se había especulado en otros estudios u opiniones acerca de la crítica de arquitectura en redes en el Perú, puede observarse que sí existe crítica con un grado importante de reflexión. El 89.4\% de la crítica identificada en las plataformas digitales implica la emisión de un juicio de valor, contiene análisis y valoración del objeto. Esta crítica con juicio de valor se efectúa independientemente de la temática desarrollada y responde a la decisión del autor frente al objeto criticado.

Blogs como Lugares Comunes o Divagarquitectura efectúan una crítica con juicio de valor al $100 \%$ y de forma regular, por lo que se diferencian claramente de los textos críticos de otros, que responden a intereses informativos. Páginas como Lucho Gris o Grandes Éxitos van por el mismo camino. Allí el método utilizado para efectuar la crítica tiene mucha importancia. Una caricatura o un fotomontaje, a manera de crítica gráfica, actúa directa y claramente en la emisión del mensaje. Estos, para generar polémica, es decir, un debate u opinión del receptor -forma válida y efectiva para amplificar la difusión de la página-, suelen estar cargados de una opinión deliberadamente debatible o cuestionable.

\section{Según el método}

El 59.2\% de la crítica emitida en estos espacios se hace por medio de textos cortos, principalmente en los blogs. Si bien no existe una limitación espacial para la extensión de las publicaciones en este tipo de plataformas, los autores de Citio y Divagarquitectura coinciden en que un texto breve es mucho más efectivo que uno extenso, pues el usuario digital suele mantener la concentración por periodos cortos. Así, un texto corto tiene mayores posibilidades de ser consumido a cabalidad.

En segundo lugar, la preferencia por un texto largo suele estar relacionada a la finalidad académica-personal. Esto quiere decir que se relativiza la extensión para priorizar la complejidad del mensaje que quiere transmitirse. No importa si el texto es consumido del todo: para el autor es más importante expresarse. En esto coinciden Javier Vera de Citio y Matteo Stiglich de Lugares Comunes. En el extremo opuesto se ubican los métodos socialmente más efectivos: las imágenes, las caricaturas, los fotomontajes, las fotos con textos muy cortos y los conocidos memes. Estos son protagonistas en las redes sociales. Es el método más efectivo para luchar en un medio caracterizado por la sobreinformación -visual-, como Facebook, donde la mayor parte de material publicado es gráfico.

Frente a este panorama resulta crucial indicar que ni el lenguaje escrito ni el gráfico es más o menos importante que el otro. Aunque parezca que la elaboración de un texto mantiene un perfil académico y sacralizado de cómo debería ser la crítica, la utilización de material gráfico requiere igual cantidad de conocimiento y habilidad para hacer que este sea socialmente efectivo y certero. Incluso, el material gráfico mantiene una vigencia y prioridad importante en plataformas digitales, por ser de rápido consumo, lo cual lo convierte en un método muy útil -e incluso necesario- en una era digital como la actual.

El recurso gráfico no es exclusivo de la arquitectura, ni siquiera de la crítica, sino que es una apreciación coyuntural de un hecho específico en la que personas -generalmente anónimas o escondidas tras seudónimosoptan por enviar un mensaje que resalta un aspecto observable de la realidad con "poca seriedad" o con un doble sentido. Esto comúnmente suele convertirse en burla, por lo que no son considerados por muchos como crítica propiamente dicha, sino como un desfogue momentáneo e incluso "inmaduro".

Esta común apreciación podría no ser tan cierta. La sociedad actual y el avance con el que se maneja la sociedad contemporánea, donde se avanza fugazmente, requiere un mensaje con estas características, en el sentido más técnico posible: que la crítica corra a la misma velocidad que la tecnología, pero sin dejarse embestir por las características negativas que estas plataformas pueden tener (García Canclini, 2007). 
Según el estilo

El $45 \%$ de la crítica desarrollada en plataformas digitales emplea un estilo bastante neutral. En este se equilibra el grado de frontalidad o violencia que puede contener la crítica, que se ve opacada por un discurso alturado. Este es el lenguaje convencional de blogs como Tipos (In)Urbanos, Lugares Comunes o Divagarquitectura. En estas páginas eventualmente se es frontal; sin embargo, se mantiene un lenguaje homogéneo y serio que permite una exploración entre ambas maneras de presentar la crítica.

Una crítica mucho más apasionada, y no por ello necesariamente menos seria, es la que desarrollan Citio, Lucho Gris o Grandes Éxitos a partir de una posición frontal y provocadora, que se convierte en el estilo particular y marca de su crítica. Este lenguaje es lo que les ha permitido una mayor recepción y recordación del público usuario de plataformas digitales. Esto devela un interés o afinidad clara por la crítica que con una opinión provocadora genera debate. Estas características son las que mantienen viva la actividad en la web 2.0, pues resultan naturalmente atrayentes.

El estilo depende íntegramente de la concepción que tiene el autor acerca de qué es o cómo debería ser la crítica. La violencia constante -en palabras de Sloterdijk (2014 [1983])-, presente en distinta medida en Grandes Éxitos y Lucho Gris, es un manifiesto de descontento en el que -al respecto sus autores coinciden- una crítica conservadora no sería suficiente. Esto no invalida las otras críticas; por el contrario, amplía el espectro temático para diversos públicos con variados intereses.

En definitiva, el estilo demuestra la elección personal del crítico o de la plataforma según los intereses que tiene. La provocación está estrechamente ligada al debate y a lo mediáticamente exitoso, mientras que lo conservador está vinculado a lo académico. Por otro lado, lo neutral se ubica en un punto intermedio y depende más de la coyuntura o la temática abordada.
Según el medio

Al ser el espacio donde la crítica se asienta, el medio se convierte en el principal agente de cambio entre la crítica tradicional y aquella desarrollada de forma digital. Los medios virtuales en todos los casos son gratuitos, tanto los blogs como las redes sociales.

Las plataformas preferidas e idóneas para los arquitectos son los blogs, una suerte de bitácoras virtuales, agendas, revistas o libros fugaces en los que los autores pueden publicar según su voluntad. El tipo de blog empleado no es determinante para el tipo de crítica, pues las variaciones entre un las posibilidades de publicación que ofrece un blog alojado en Blogspot y uno en Wordpress son mínimas.

La posterior masificación de las redes sociales -como en todo espacio cultural contemporáneo- ha opacado en gran forma el trabajo publicado en blogs. El principal motivo es la interacción que se genera en una red social. Facebook, recién en 2014, se convirtió en una plataforma dinámica de crítica de arquitectura en el Perú, cuando ya otros países, como Argentina o España, habían participado de ello desde 2012.

Según el alcance

El alcance temático-espacial de la crítica en estos medios se desprende del interés del autor o la plataforma (página o blog). Espacios como Tipos (In)urbanos y Lugares Comunes centran su crítica en el análisis de hechos locales de Arequipa y Lima, respectivamente. Citio tiene la misma orientación, aunque la alterna a menudo con una temática de alcance nacional.

La crítica de interés local gira principalmente en torno a la temática de la ciudad. La crítica de interés nacional alterna entre la ciudad y el edificio, pero sobre todo lidia con el ejercicio profesional y aborda temas que conciernen a un amplio número de arquitectos, al margen de las barreras geográficas locales. Este es el caso de Citio, Habitar, Divagarquitectura, Grandes Éxitos y Lucho Gris. Por ejemplo, la reflexión y crítica alrededor de la XVI Bienal de Arquitectura Peruana (2014): en varios de 
los espacios mencionados se generó un debate que atravesaba los límites geográficos locales. La importancia de esto radica en que, a diferencia de los espacios tradicionales o académicos, el debate se generó al instante, y la presencia del contra-crítico o crítico diletante (quien comenta) fue también masiva.

En este punto radica la trascendencia espacial de la crítica en la web 2.0: en que un tema se vuelva de interés nacional, y no tanto en que se hable en "igualdad de condiciones" sobre temas referentes a diversos lugares del país.

Con respecto a la crítica de alcance temático-espacial internacional, se realiza crítica directa de edificios del extranjero, material expuesto prioritariamente por Habitar y $D i-$ vagarquitectura, así como discusiones críticas y teóricas que no se circunscriben a un límite geográfico específico.

Llama la atención que a pesar de que las redes sociales como Facebook intensifiquen la difusión espacialmente ilimitada, el interés temático de la crítica emitida en estas páginas no esté centrado en temas internacionales, sino en temas eminentemente peruanos. Esto se debe a un interés de los autores por establecer un público específico, lo cual responde a que el fin de estos espacios es prioritariamente mediático y social. El espíritu provocador es más fácil de desarrollar frente a un tema conocido por los autores, pero también por el público. Este hecho fortalece la fidelidad del público consumidor para con el medio/autor de tal forma que vuelve predecible la crítica futura efectuada por el autor y mantiene la constancia de los seguidores.

El alcance que tienen páginas como Grandes Éxitos o Lucho Gris demuestra que el ejercicio de la crítica, con la que varios están de acuerdo y otros no, está tomando otros caminos, caminos que ciertamente han sido recorridos antes (como en el caso de la Agrupación Espacio) y que no pueden negarse ni evitarse, pues ya forman parte de una posición crítica frente a la realidad, la cual implica una llamada de atención ética y estética, ya sea que su modo de operar esté muy cerca de formas violentas y políticamente incorrectas (en Grandes Éxitos), o se lleve a cabo de forma más responsable (en Divagarquitectura o Habitar):

Para todo sistema en desarrollo serían imprescindibles un cierto grado de ironía y un pequeño ángulo de visión revolucionario. Sin duda, el funcionalismo niega a la conciencia humana no sólo el derecho de emancipación de las normas y necesidades, pues ésta le conduce en línea recta hacia la nada, hacia un individuo, hacia un caos anónimo y hacia la pérdida de estructura de las sociedades (Sloterdijk, 2014, p. 86).

Un aspecto positivo es que, como se trata de un objeto estático, es posible que la crítica permanezca en la web "por siempre", que se pueda recurrir a ella en el futuro. Esa es una característica del sistema de producción de crítica en plataformas digitales: la información puede ser constantemente consumida, sin un límite temporal o geográfico.

\section{Según la sostenibilidad}

La sostenibilidad de la crítica es de suma importancia, pues solo una crítica constante puede cumplir con una labor social a cabalidad. A excepción de Citio, los blogs mencionados en este estudio han mantenido un periodo constante de publicación (crítica), acorde con su tiempo de existencia. Ello se debe a que algunas de las plataformas no fueron creadas para dedicarse exclusivamente a la crítica, sino como un espacio para verter opiniones varias. Este es el caso particular y notorio de Divagarquitectura, blog que nació como una bitácora de viaje y luego penetró con amplitud en la crítica.

El caso de Citio es particular, pues tuvo una época de producción constante (en los primeros cuatro años) que cesó tras la paralización de labores del colectivo, a pesar de que seguían publicando eventualmente. A diferencia de los blogs, las páginas en redes sociales sí han mantenido constancia en las críticas emitidas desde su creación, ya que su principal finalidad fue desde el principio la emisión de una posición crítica. 


\section{Conclusiones}

Las plataformas digitales aquí mencionadas, que aparecieron a mediados de la década de 2000, nacen como espacios de socialización y de intercambio de información, como manifestación clara de una revolución digital en la que la arquitectura se encuentra inmersa. Así, existe una cantidad considerable de crítica que se desarrolla en plataformas digitales. Esto lo demuestran los 30 espacios de crítica que se ha podido encontrar durante un lapso de ocho años, distribuidos entre blogs y redes sociales operados desde distintas ciudades del país, independientemente de los diversos espacios universitarios. Esto último parece demostrar que muchas barreras académicas están empezando a disolverse gracias a los espacios digitales.

Aunque gran parte de esa crítica mantiene la rigurosidad de los espacios tradicionales, esta muchas veces se debate en el mismo escenario que discursos plagados de expresiones triviales, que bajo el nombre del espíritu crítico e imbuidos por el derecho del "vale todo", opacan y relativizan las iniciativas más serias y conscientes del quehacer crítico, y de la mejora arquitectural. Este debate de igual a igual se presenta como un problema común en estos espacios, que va en aumento. Así como existen manifestaciones sumamente positivas, existen expresiones que demuestran un espíritu crítico en su estado más irracional e irresponsable.

Se necesita una crítica didáctica que enseñe o introduzca el interés por la labor crítica en un contexto en el que esta se ha mostrado siempre esquiva. Pero también se requiere que la crítica, como afirma Peter Sloterdijk (2014), tenga ingredientes activos $\mathrm{y}$, hasta cierto punto, violentos, pues dentro del mundo efervescente que es su público objetivo existirá quienes, conscientes de la realidad y capaces de absorber racionalmente los bombardeos de la época (Massad, 2015), puedan tener en cuenta, en el futuro, las llamadas de atención o las actitudes de quienes intentaron la crítica antes.
Ambas visiones y modos de operar -con sus múltiples matices y aspectos, tanto positivos como negativos- son expresiones que tratan de aprovechar estas plataformas. Estos espacios, al contar con una década de existencia, probablemente crezcan tanto en número como en su grado de rigor respecto del saber teórico y crítico. Lo trascendente no son las expresiones que hoy se desarrollen, sino el hecho de que estas abren un panorama mucho más extenso y real acerca de la crítica de arquitectura, y del sentir y la posición de sus protagonistas, así como también amplía el número de potenciales críticos que se ven influenciados por estas primeras muestras.

Ya que son el principal espacio de comunicación social actual, las plataformas digitales serán donde la crítica se seguirá desarrollando como complemento del espacio real y académico convencional. Por ello resulta importante replantear la concepción de la crítica, incluso desde la consistencia de los actores en su sistema de producción: el crítico puede ser invisible o colectivo; la crítica es multiforme y fugaz; el medio puede ser creado, regulado, orientado y socializado por el propio crítico, o por grupos de interesados en el tema; el comitente o el editor puede ser prescindible. Hoy, además, se trata de un espacio que diagnostica con fidelidad la visión crítica sobre la arquitectura peruana: una visión de múltiples intereses, perspectivas, prioridades y búsquedas que demuestran un panorama sumamente heterogéneo, en el que muchos de sus actores -a diferencia de épocas pasadastienen la posibilidad de hablar por sí mismos (López Soria, 2007).

La experiencia de la crítica en plataformas digitales debería impactar en la crítica tradicional y el espacio académico, e incluso fomentar que estos se replanteen. 


\section{Referencias}

Eco, U. (2015). Interpretación y sobreinterpretación. Madrid, España: Akal. Primera edición de 1992.

García Canclini, N. (2007). Lectores, espectadores e internautas. Barcelona, España: Gedisa.

Lash, S. (2002). Crítica de la información. Madrid, España: Amorrortu.

López Soria, J. I. (2007). Adiós a Mariátegui. Pensar al Perú en perspectiva posmoderna. Lima, Perú: Congreso de la República.

Massad, F. (2015). La viga en el ojo. Escritos a tiempo. Madrid, España: Asimétricas.
Montaner, J. M. (2007). Arquitectura y crítica. Barcelona, España: Gustavo Gili.

Sloterdijk, P. (2014 [1983]). Crítica de la razón cínica. Madrid, España: Siruela.

Stroeter, J. (2005) Arquitectura y forma. México DF, México: Trillas.

Toca, A. (2011, 03 de mayo). Más crítica y menos crónica. Recuperado de http://expansion.mx/ obras/2011/05/03/critica-arquitectura-medioscomunicacion 